\title{
ANALYTICAL METHOD FOR DESIGNING FSS-BACKED REFLECTARRAY ANTENNA USING TRANSMISSION LINE APPROACH
}

\author{
Iman Derafshi, Nader Komjani and Ensiyeh Ghasemi-Mizuji \\ Department of Electrical Engineering, Iran University of Science and Technology, Tehran 1684613114, Iran, \\ e-mail:iman_darafshi@elec.iust.ac.ir,n_komjani@iust.ac.ir,ensiyeh.ghasemi@ee.iust.ac.ir
}

\begin{abstract}
The main purpose of this paper is introducing a new method based on the transmission line approach for designing FSS-backed reflecarray antennas. For this reason a dual band reflectarray antenna is designed. This antenna contains a conventional single layer RA and a FSS backed double layer RA with $54 \%$ and $50 \%$ efficiency operating at $X$ band and $K$ band, respectively. A double layer FSS is used between RAs to isolate them. $K$ band cell element is designed and analyzed using transmission line method and consideration of equivalent circuit for elements of each layer. Then the results obtained using this technique is compared to those found by CST and ADS. The comparison shows a good agreement. Jerusalem cross dipole with variable size is employed as radiation element in both bands. The most important properties of our suggested array are low cross polarization and high efficiency.
\end{abstract}

Index Terms - Reflectarray Antenna (RA), Frequency Selective Surface (FSS), Transmission Line Method, Dual Band Antenna.

\section{INTRODUCTION}

Today, reflectarray antennas (RAs) are utilized in many applications because of their numerous advantages. These antennas consist of reflective elements etched on a flat surface and a prime feeding antenna illuminates these elements. Each reflective element introduces a pre-adjusted phase shift to produce a constant phase front.

The most drawback of RAs is their narrow bandwidth. To overcome this disadvantage several multiband and broadband antennas have been used to increase the band width [1-9]. Multi band antennas can be implemented in single layer or multilayer configuration [1-9]. The former is used when frequency are close and the latter used for wide frequency applications. An efficient technique to design multilayer, multiband configuration is using FSS between reflective layers as band isolator, which has been suggested in [1]. Also, in [2] a dual band X/Ku RA is implemented by this method.

In this study an analytical method is investigated to design FSS-backed RAs for the first time. So, a lot of optimization methods in MATLAB can be utilized to optimize FSS parameters for better performance. In this proposed method equivalent LC circuit is considered for each layer and with the use of transmission line theory the impedance of whole structure is calculated. Also, transmission and reflection coefficients are obtained. Using this analytical method a FSS-backed dual band, dual polarized RA is designed in $\mathrm{K}$ band and $\mathrm{X}$ band RA is designed with the conventional method 
mentioned in [10]. This cascade configuration is composed of two arrays: a single layer conventional $\mathrm{X}$ band array and a double layer FSS-backed K band array.

The proposed antenna shows a remarkable performance at both $\mathrm{X}$ and $\mathrm{K}$ bands (10.4-11.4 GHz and 20- $22.1 \mathrm{GHz}$ ) with efficiency of around $50 \%$ and $54 \%$, respectively. The FSS placed between two arrays acts as ground plane in $\mathrm{K}$ band and has transmission property at $\mathrm{X}$ band. Also, this applied FSS layer creates isolation and reduces mutual coupling between the two proposed frequency bands. Because of utilizing polarization insensitive unit cell, the designed antenna has similar operation for both polarization and has a very low cross polarization.

\section{DEVELOPMENT OF THE PROPOSED ANTENNA}

As mentioned previously FSS-backed configuration is a suitable choice when operation bands are apart. In this technique the upper band FSS-backed RA is located on top of the lower band metalbacked RA. The schematic diagram of this configuration is shown in figure 1. Also, The prototype of the antenna and cell element of each layer are specified in figure 1.

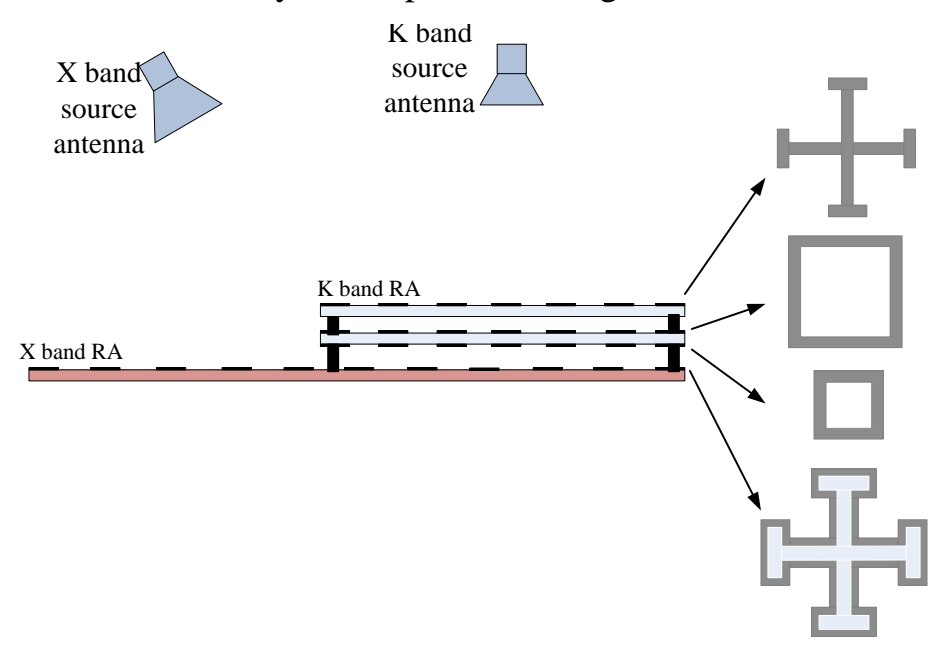

Fig. 1. Schematic of the proposed antenna.

The parameters of FSS-backed antenna are adjusted in order to reflects incident waves at $\mathrm{k}$ band (20-22 GHz). and transmits them at X band (10.4-11.4 GHz). Using double layer FSS element gives more degrees of freedom for optimizing parameters to have broadband FSS with mentioned properties. Furthermore, using FSS physical and electrical isolation is achieved, additionally as it can be understand from [11] as larger space between layers results in lower mutual coupling so the mutual coupling between the RAs is decreased by placing FSS between them. In this article a double layer FSS is utilized as band isolator which gives more degrees of freedom for optimization. For studying dual band operation, at first step each antenna is simulated using CST software, separately. In the next step all the structure (contain both $\mathrm{X}$ and $\mathrm{K}$ band antennas) is simulated to confirm suitable performance of the antenna. All the simulations are done using time domain solver. 


\section{OBTAINING K BAND RA PARAMETERS WITH USE OF TRANSMISSION LINE METHOD}

A frequency selective surface consists of an array of periodic structures that used to control incident wave in different ways such as filtering, isolating and changing phase and amplitude. As it noted previously, the insertion of FSS between RAs reduces the mutual coupling between layers and improve their isolation. If the layers have enough physical distance and the dielectric constant of the substrate is small enough, mutual coupling can be ignored and RA layers have little effect on each other and they can be designed and analyzed separately. In this section new method is suggested to design and analyze FSS-backed unit cell.

$\mathrm{K}$ band unit cell is depicted in figure 2.a. In this unit cell, the Jerusalem cross dipole is used as phasing element and the phase shift is compensated by variation of $l_{d}$ (Fig.2.b). This reflective layer is located on top of the FSS layer with $2 \mathrm{~mm}$ spacer (Fig.2.c and d). Rohacell foam (er=1.05, tan $\mathrm{d}=0.0003$ ) can be used as spacer to keep antenna layers together [14]. An array of square rings is etched on both sides of lower substrate to operate as FSS. All of the substrates are 32-mil RO-4003. The equivalent circuit of this unit cell is presented in figure 2.f. In figure 2.f $\eta_{0}$ and $\eta_{d}$ are the free space and the substrate impedances, respectively.
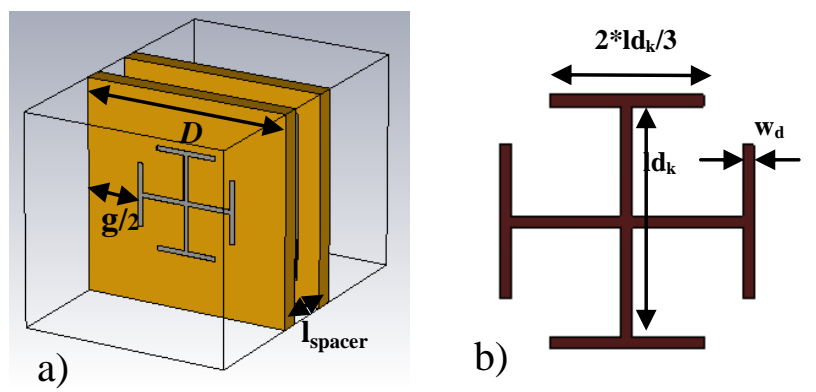

c)

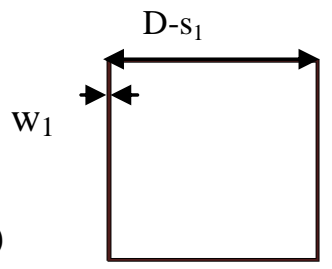

d)

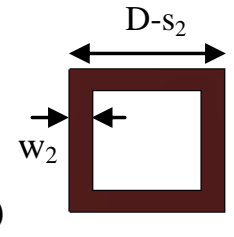

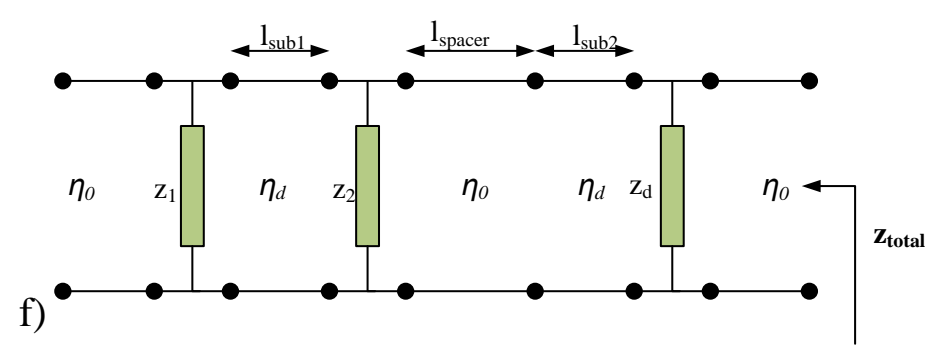

Fig.2. a)The K band unit cell. b) Reflective element. c) first FSS layer element. d) Second FSS layer element. f) Equivalent circuit.

The impedance of lower FSS layer, $z_{1}$, the impedance of upper FSS layer, $z_{2}$, and the reflective element impedance, $z_{\mathrm{d}}$, are described by following equations [12-13].

$$
\begin{aligned}
& C_{i}=4 \varepsilon_{0} \varepsilon_{e f f}\left(\frac{(D-s) \cos (\theta)}{2 \pi}\right) H(D, s, \lambda, \theta) \\
& L_{i}=4 \mu_{0} \mu_{e f f}\left(\frac{(D-s) \cos (\theta)}{2 \pi}\right) H(D, s, \lambda, \theta) \\
& i=1 \text { or } 2
\end{aligned}
$$




$$
\begin{aligned}
& H=\ln \left(\sin \left(\frac{\pi s}{2 D}\right)^{-1}\right)+G(D, s, \lambda, \theta) \\
& G=\frac{.5 B_{1}\left(B_{2}\left(A_{+}+A_{-}\right)+4 \beta^{2} A_{+} A_{-}\right)}{B_{2}+B_{3}\left(A_{+}+A_{-}\right)+2 \beta^{6} A_{+} A_{-}} \\
& \beta=\sin \left(\frac{\pi s}{2 D}\right) \\
& B_{1}=\left(1-\beta^{2}\right)^{2} \\
& B_{2}=1-\frac{\beta^{2}}{4} \\
& B_{3}=1+\frac{\beta^{2}}{4}-\frac{\beta^{3}}{8} \\
& L_{d}^{T E}=\frac{\eta_{0} D}{2 c \pi} \ln \csc \left(\frac{\pi w}{2 D}\right)\left(1-2 \frac{\sin ^{2} \theta_{s}}{\varepsilon_{r}+1}\right) \\
& L_{d}^{T M}=\frac{\eta_{0} D}{2 c \pi} \ln \csc \left(\frac{\pi w}{2 D}\right) \\
& C_{d}=\frac{\varepsilon_{0} \varepsilon_{r} d}{\pi}\left[\ln \csc \left(\frac{\pi w}{2 D}\right)+F\right] \\
& F=\frac{\sqrt{1-\left(\frac{d}{\lambda}\right)^{2}} u^{2}}{1+\sqrt{1-\left(\frac{d}{\lambda}\right)^{2}}\left(1+u^{2}\right)} \\
& u=\cos ^{2}\left(\frac{\pi g}{2 D}\right) \\
& \lambda=\frac{2 \pi}{k_{0} \sqrt{\frac{\varepsilon_{r}+1}{2}}}
\end{aligned}
$$

The required parameters are shown in figure 2. After computing $\mathrm{z}_{\mathrm{total}}, \mathrm{S}$ parameters can be found by equations 15,16 and 17 .

$$
\begin{gathered}
S_{11}=|\Gamma|^{2} \\
S_{21}=1-|\Gamma|^{2} \\
\Gamma=\left|\frac{\eta_{0}-z_{\text {total }}}{\eta_{0}+z_{\text {total }}}\right|
\end{gathered}
$$

Where $\mathrm{z}_{\mathrm{total}}$ is the total impedance of the unit cell structure (Fig.2.f). Employing MATLAB for designing FSS-backed unit cell takes more degrees of freedom for choosing optimization algorithm. After obtaining parameters, they are investigated using CST to find the optimum values of the unit cell parameters. The total values of $K$ band cell element parameters are as: $1_{\text {spacer }}=2 \mathrm{~mm}, \mathrm{D}=9 \mathrm{~mm}$, $\mathrm{w}_{\mathrm{d}}=0.2 \mathrm{~mm}, \mathrm{~d}=2 * \mathrm{ld}_{\mathrm{k}} / 3, \mathrm{w}_{1}=0.6 \mathrm{~mm}, \mathrm{w}_{2}=0.1 \mathrm{~mm}, \mathrm{~s}_{1}=5 \mathrm{~mm}, \mathrm{~s}_{2}=2 \mathrm{~mm}$. 
The S parameters obtained with explained method is compared with the S parameters from CST and ADS in figure 3. The ADS S parameters are achieved by the technique mentioned in [12]. These curves are drawn for the parameters mentioned above and $\mathrm{ld}_{\mathrm{k}}=2.5 \mathrm{~mm}$ and $\theta_{\mathrm{s}}=0$ (normal incidence). From these figures it is obvious that the curves achieved by different simulators match with each other very well. To explore performance with variation of phasing element size, S11 and S21 amplitudes for different values of ld are demonstrated in figure 4. Results show good transmission and suitable reflection for various sizes of phasing elements at $10-12 \mathrm{GHz}$ and at $20-23 \mathrm{GHz}$, respectively. As it is clear from figure 4 the designed FSS- backed unit cell shows suitable performance in a wide frequency range at both bands. The reflection phase and amplitude at $\mathrm{K}$ band and transmission amplitude at $\mathrm{X}$ band are brought in figure 5 with use of CST parameter sweep. Phase variation of about 360, reflection amplitude better than $0.3 \mathrm{~dB}$ at $21 \mathrm{GHz}$ and appropriate transmission amplitude (better than $0.7 \mathrm{~dB}$ ) at $11 \mathrm{GHz}$ are attained by this unit cell.

The effect of incident wave angle is an important issue which should be considered to have broad band performance. The phase and amplitude of S11 are plotted in figure 6.a and b. As it is clear from figures, this unit cell is less sensitive to the incident angle. Furthermore, the discussed unit cell has a very low cross polarization. In figure 7 cross polarization versus length of ld is drawn for different frequencies.

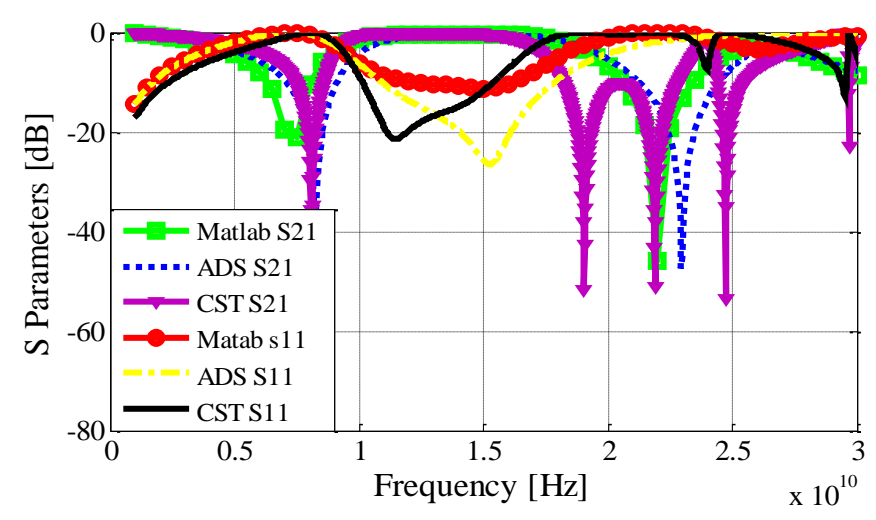

Fig. 3. S21 and S11 amplitude versus frequency.

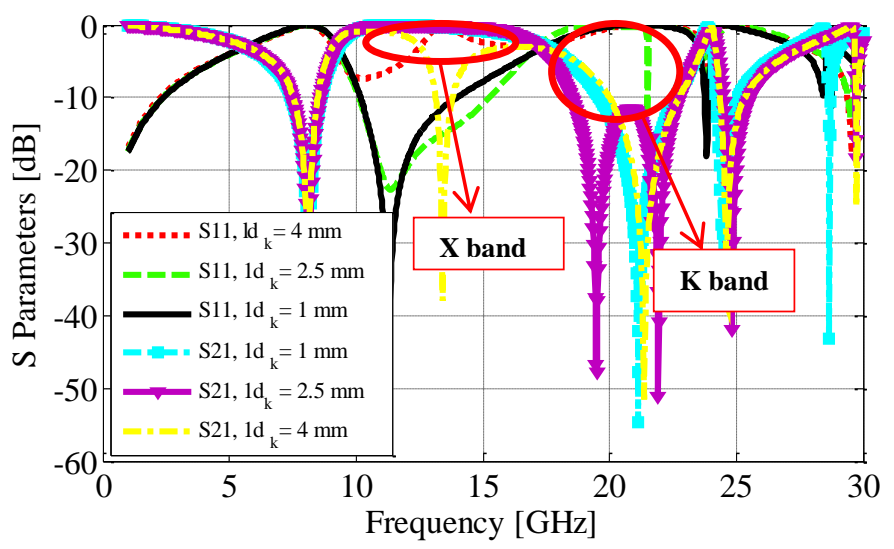

Fig. 4. S11 and S21 amplitude for different length of $\operatorname{ld}_{k}$. 

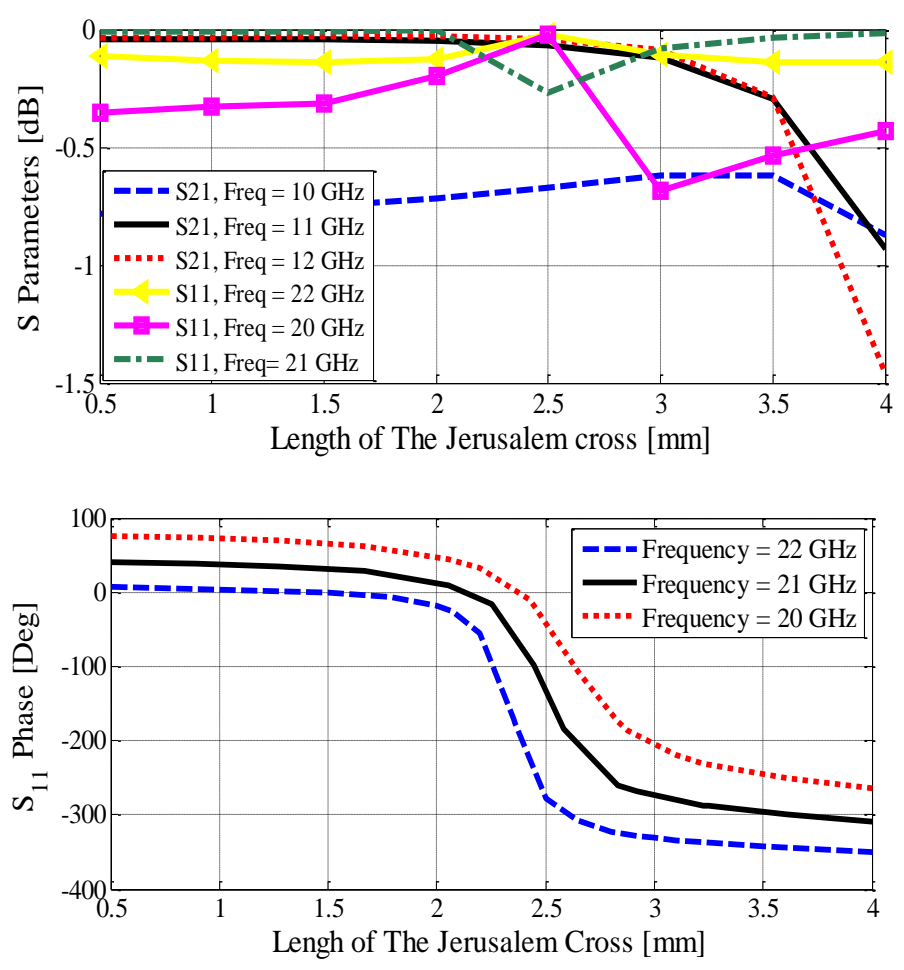

Fig. 5. a) S21 amplitude at X band and S11 amplitude at K band b) phase of $S 11$ at $K$ band versus length of $1 d_{k}$.
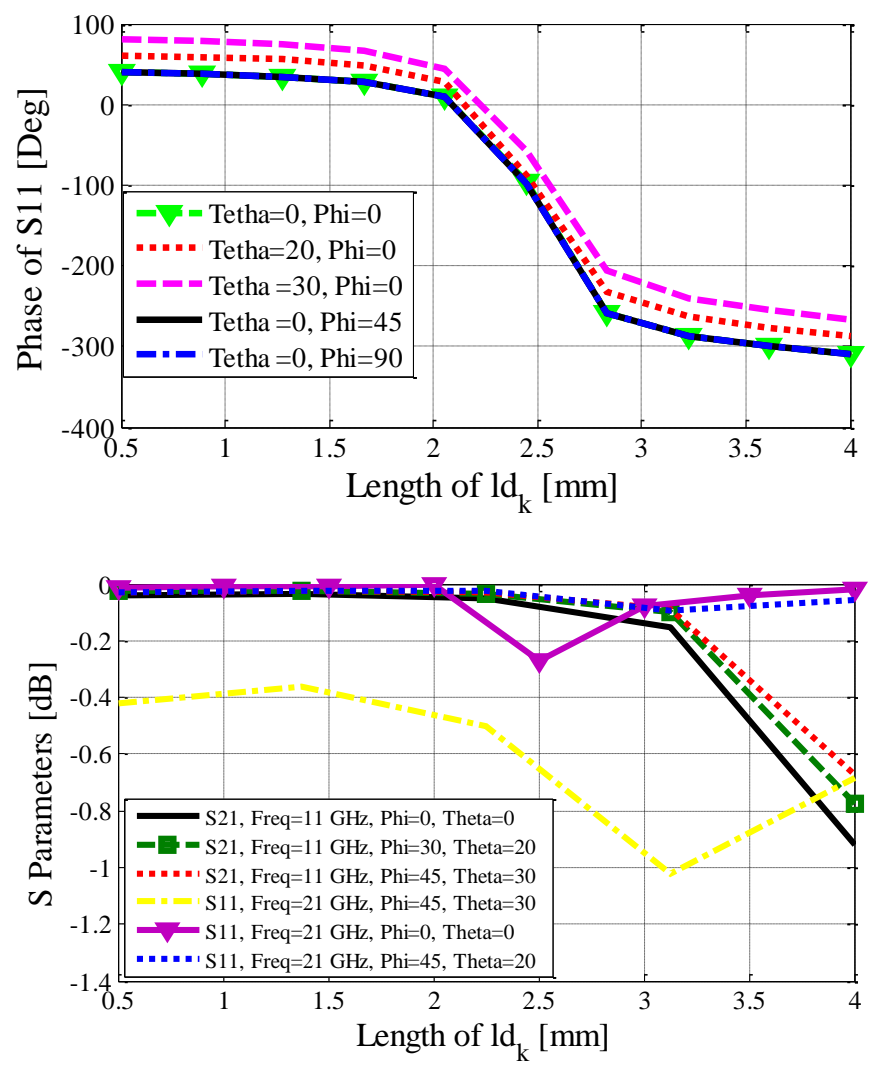

Fig. 6. a) S11 phase at $21 \mathrm{GHz}$, b) S11 amplitude at $21 \mathrm{GHz}$ and S21 amplitude at $11 \mathrm{GHz}$. 


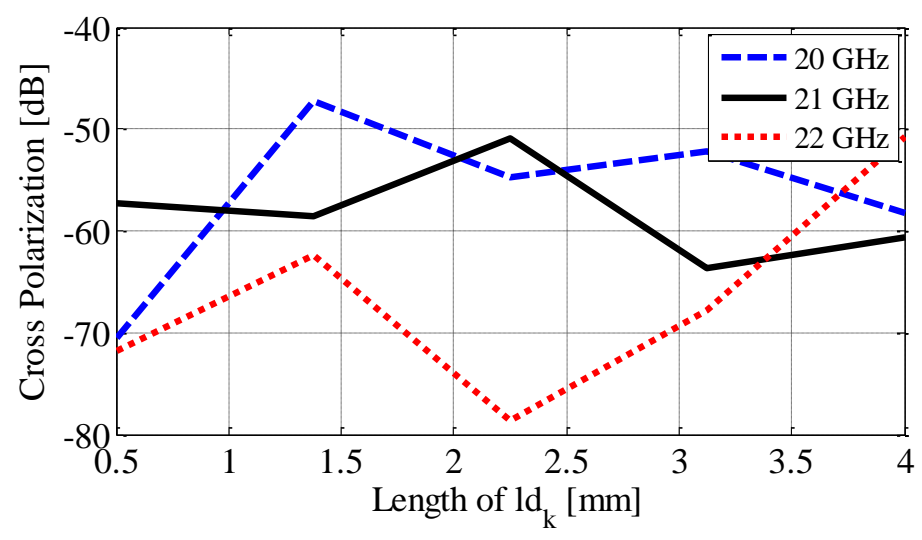

Fig. 7. cross polarization versus length of $\operatorname{ld}_{\mathrm{k}}$ for different frequencies.

The Figures 8 and 9 present current surface distribution of the suggested element under illumination of the y-polarized incident plane wave at $21 \mathrm{GHz}$ and $11 \mathrm{GHz}$, respectively. These figures are drawn for different phases of propagative wave at both $21 \mathrm{GHz}$ and $11 \mathrm{GHz}$. As it is seen, the current in the $\mathrm{y}$ direction is stimulated and current in the $\mathrm{x}$ direction is near zero at $21 \mathrm{GHz}$ so this structure has low cross polarization. The incident current flow at $11 \mathrm{GHz}$ is near zero which means the incident wave is mostly transmitted at this frequency as it is expected.

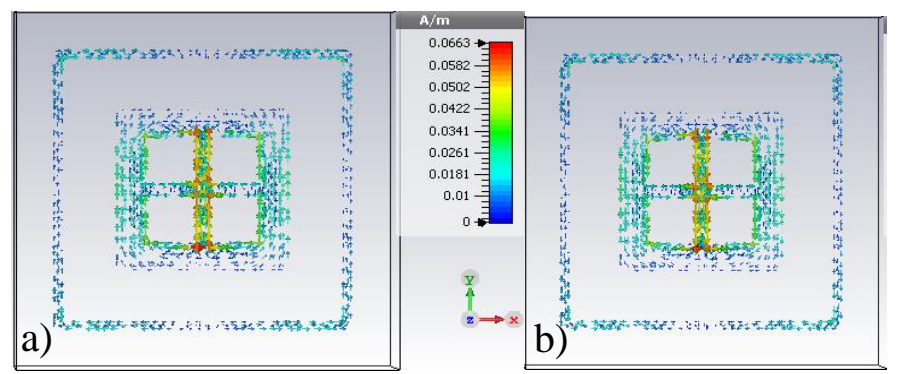

Fig. 8. Current distribution at $21 \mathrm{GHz}$ for $\mathrm{ld}_{\mathrm{k}}=3 \mathrm{~mm}$. a) Phase of incident wave is 0 . b) Phase of incident wave is 180 .

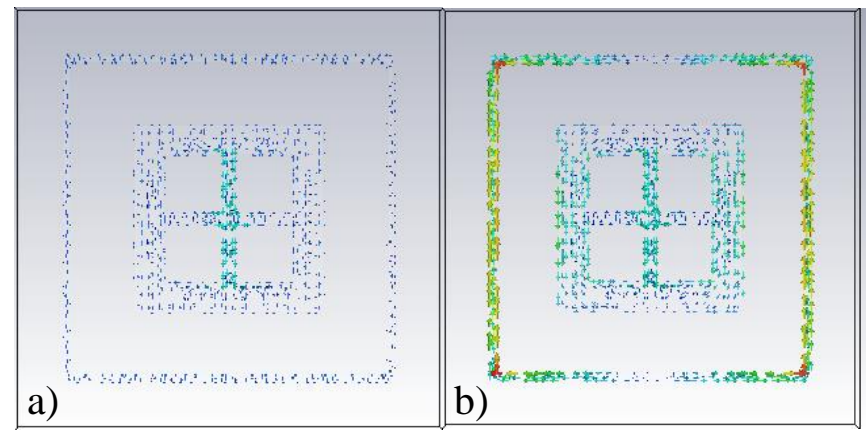

Fig. 9. Current distribution at $11 \mathrm{GHz}$ for $\mathrm{ld}_{\mathrm{k}}=3 \mathrm{~mm}$. a) Phase of incident wave is 0 . b) Phase of incident wave is 90 .

\section{K BAND ARRAY}

Using the unit cell element obtained in section II, $16.2 \mathrm{~cm} \times 16.2 \mathrm{~cm}$ array is simulated. At first step the required phase distribution on the array surface is computed with MATLAB and drawn in figure 10-a. The simulated array using CST is shown in figure 10-b. The array is illuminated by a linearly polarized horn antenna. 
The synthesized gain using MATLAB, the gain from CST and cross polarization is sketched in figure 11. According to these results, the antenna has the maximum gain of $29 \mathrm{~dB}$ ( $50 \%$ efficiency) and $-40 \mathrm{~dB}$ cross polarization. The antenna gain versus frequency is plotted in figure 12 which proves $10 \%$ bandwidth for $1 \mathrm{~dB}$ gain variation. In section $\mathrm{V}$ these results are compared with previous works.

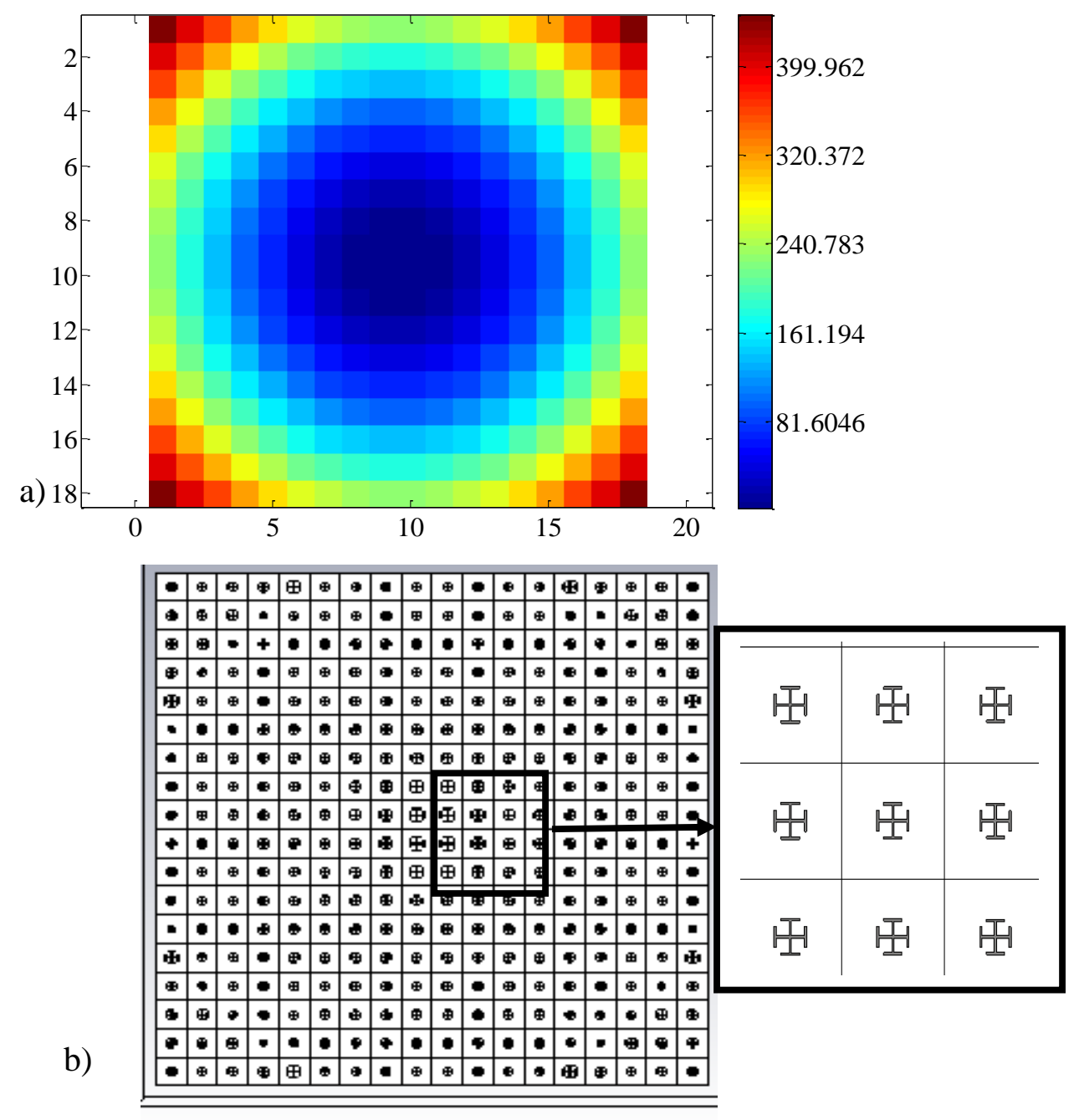

Fig. 10. a) Phase distribution. b) The simulated array.

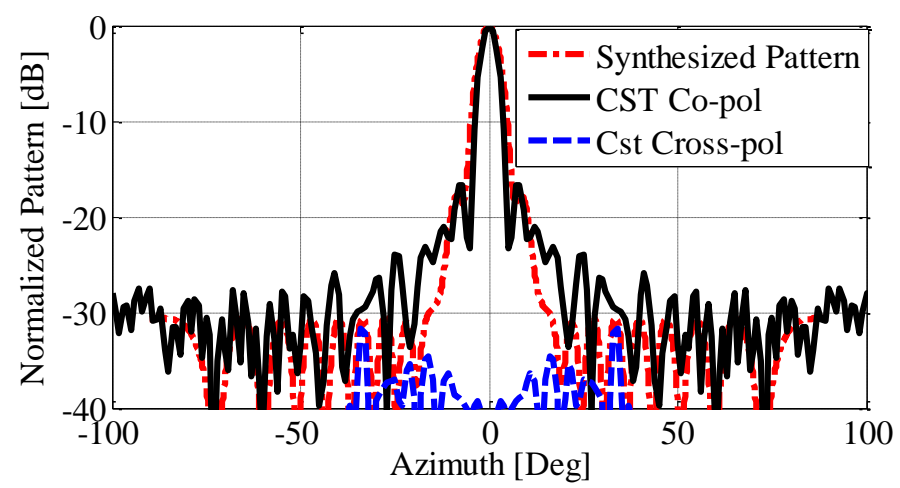

Fig. 11. K band pattern. 


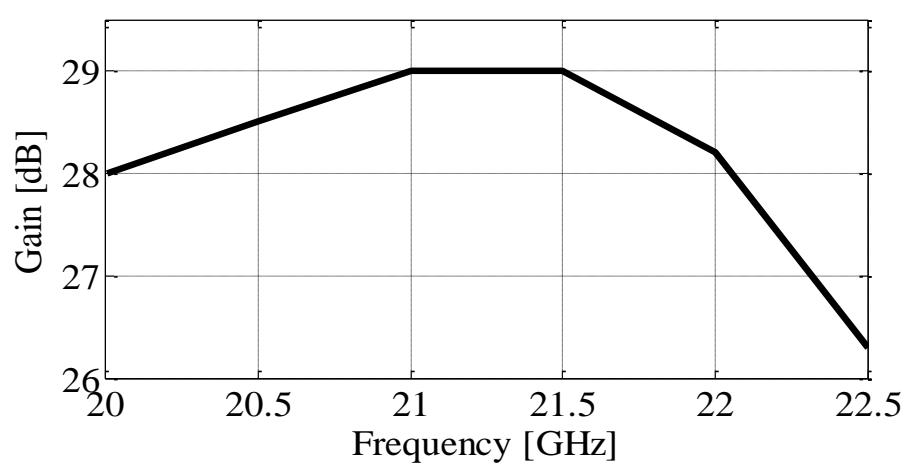

Fig. 12. Gain versus frequency.

\section{X BAND ARRAY}

A conventional metal back unit cell is used at $\mathrm{X}$ band. Phasing element is the Jerusalem cross dipole depicted in figure 13. The adjusted parameters for this unit cell are shown in figure 13 and they are as: $1_{\mathrm{u}}=13 \mathrm{~mm}, 1_{\mathrm{s}}=2 \mathrm{~mm}, \mathrm{w}=1 \mathrm{~mm}$. More than 700 degree phase variation is achieved with this modified element. Phase variation versus length of $l_{d}$ are shown in figure 14 for normal incidence at different frequencies and figure 14-b shows phase variation for different incident angles. The results prove $\mathrm{X}$ band unit cell has little sensitivity to the incident angle.

Symmetric shape of the suggested unit cell leads to have low cross polarization. This characteristic is investigated in figure 15. Also, Surface current is drawn for the unit cell at $11 \mathrm{GHz}$ under illumination of a y-polarized incident wave (figure15). As it is seen, surface current is induced in y direction. The results of these figures prove little cross polarization at different frequencies.

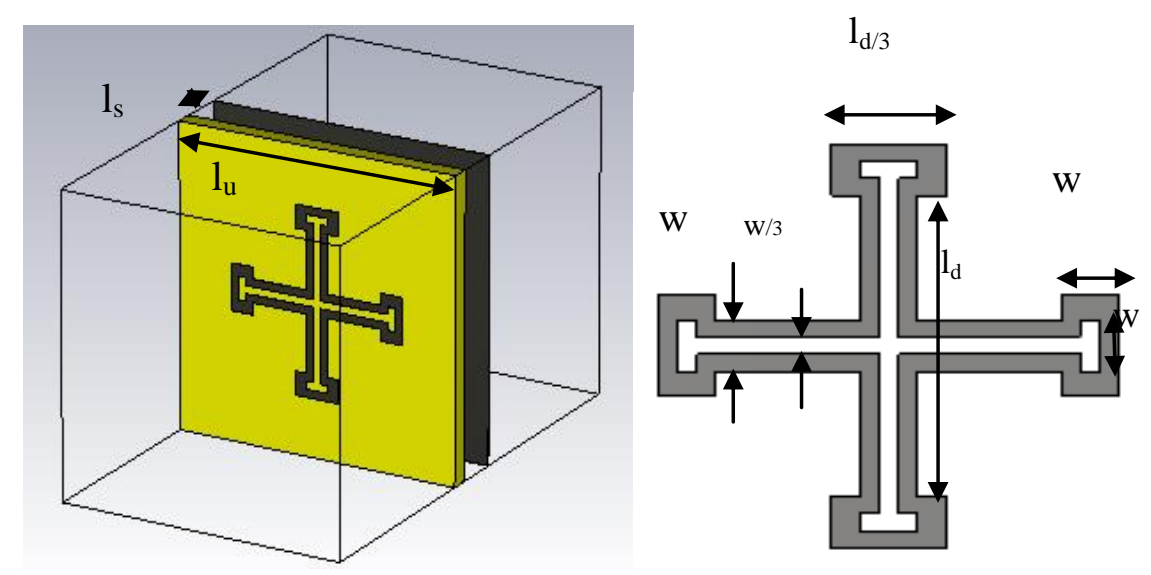

Fig. 13. X band reflective element. 

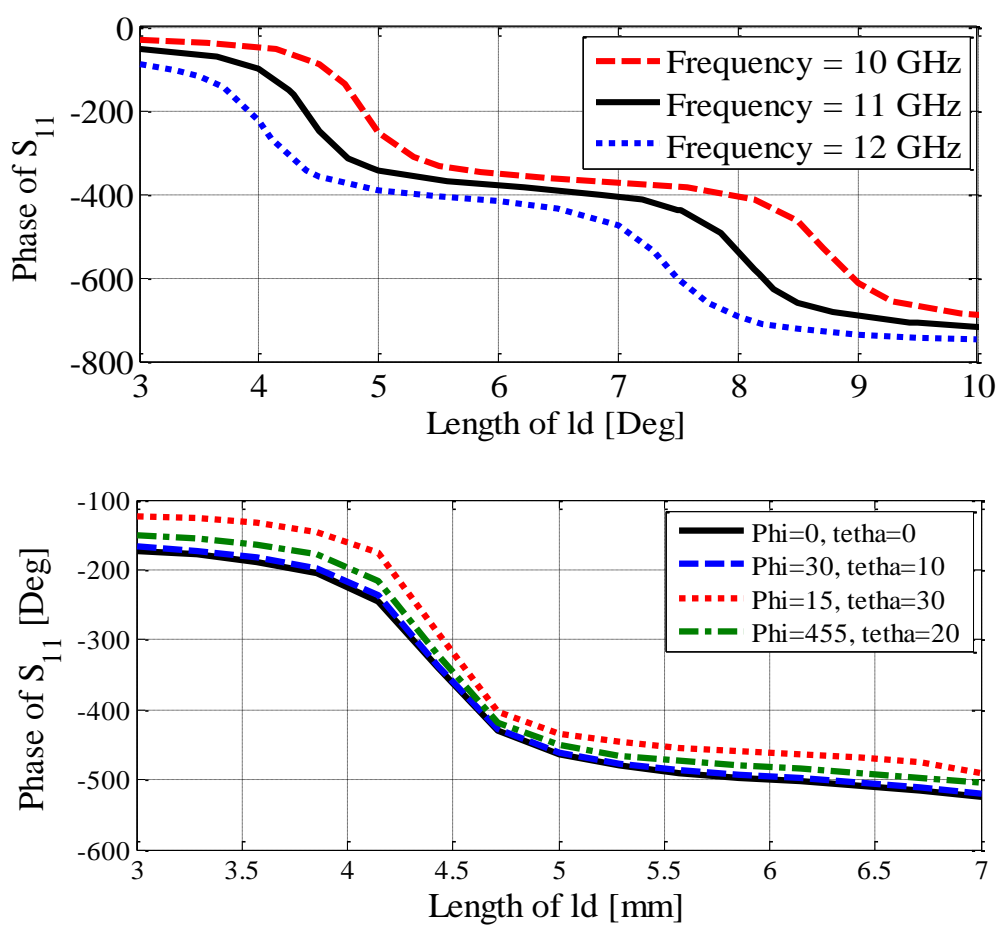

Fig.14. S11 phase variation versus length of ld a) for different frequencies b) for different incidence angle.

To study this modified unit cell performance, a $28.6 \mathrm{~cm} \times 28.6 \mathrm{~cm}$ array is designed and $32 \mathrm{mil}$ RO4003 is considered as substrate. Figure 17-a shows phase distribution on the surface of this array and figure 17-b is the array simulated using CST.

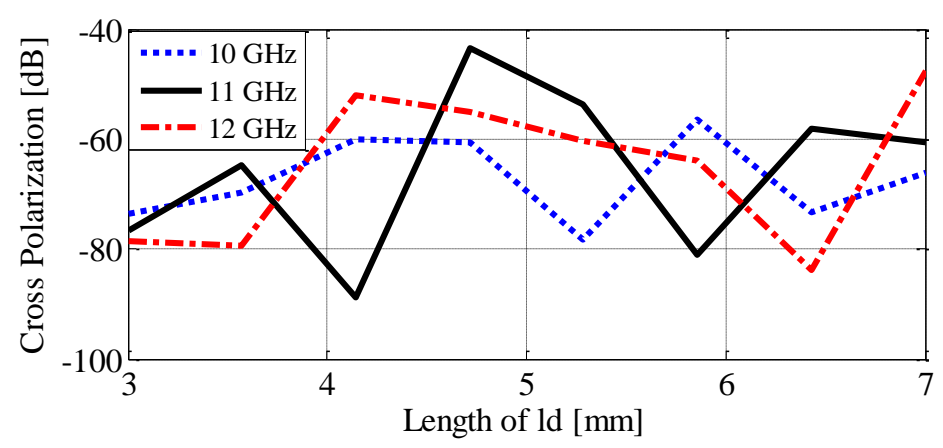

Fig. 15. Cross polarization versus length of ld.

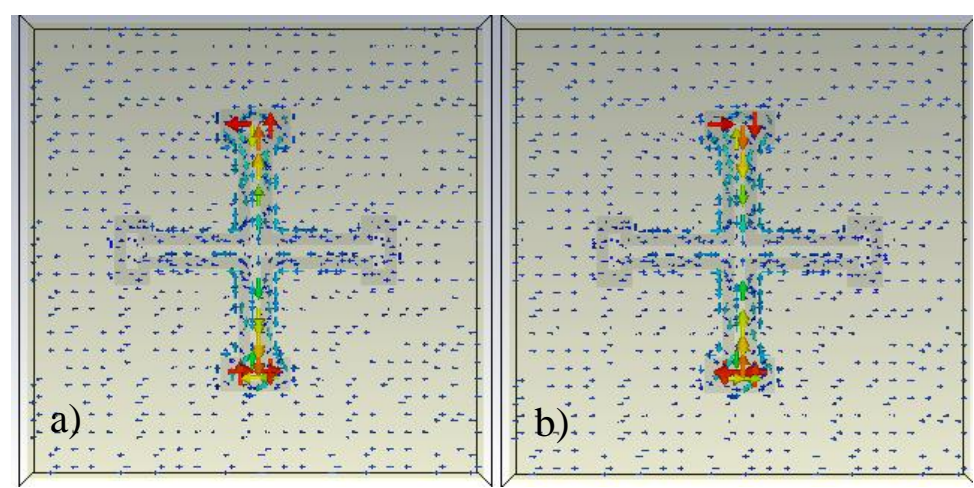

Fig. 16. Current flow at $11 \mathrm{GHz}$. a) Phase of incident wave is 0 . b) Phase of incident wave is 180. 
a)

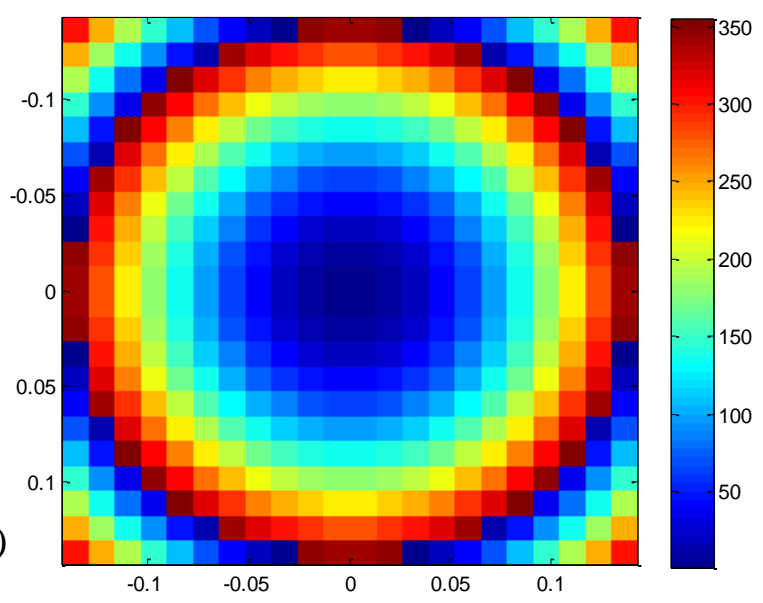

b)
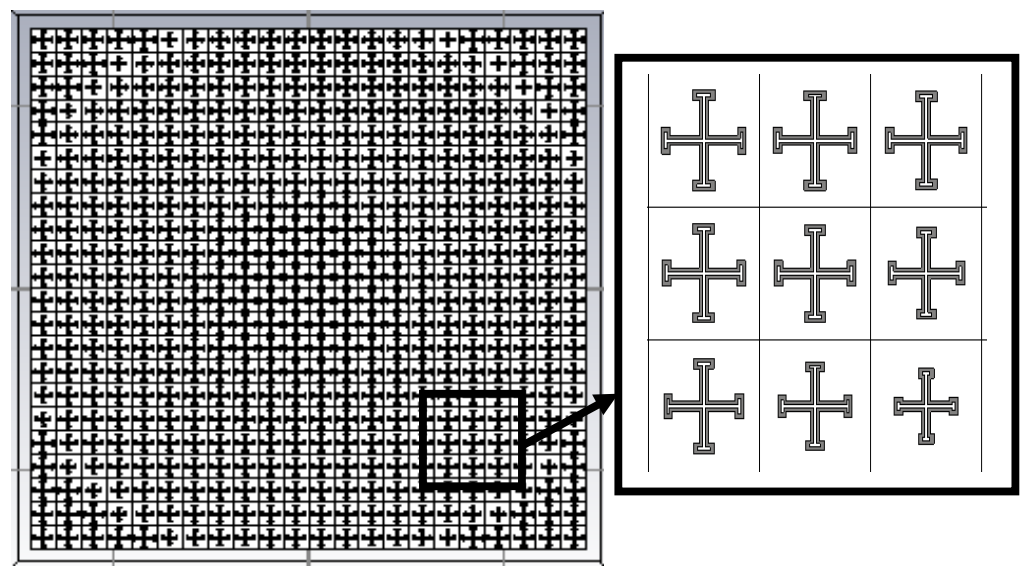

Fig. 17. a) Phase distribution on the $X$ band surface. $b)$ The simulated array using CST.

To achieve dual band performance, $\mathrm{K}$ band array is placed on top of the $\mathrm{X}$ band. A $2 \mathrm{~cm}$ spacer separates $\mathrm{X}$ and K RAs. The simulated co and cross polarization at $10.75 \mathrm{GHz}$ are brought in figure 18. The efficiency of $\mathrm{X}$ band antenna is $60 \%$ and after placing $\mathrm{K}$ band it is reduced to $54 \%$. A $0.5 \mathrm{~dB}$ insertion loss is demonstrated from the figure. Figure 19 shows the simulated gain versus frequency which verifies $1 \mathrm{~dB}$ gain bandwidth of $9 \%$ for $\mathrm{X}$ band in presence of $\mathrm{K}$ band.

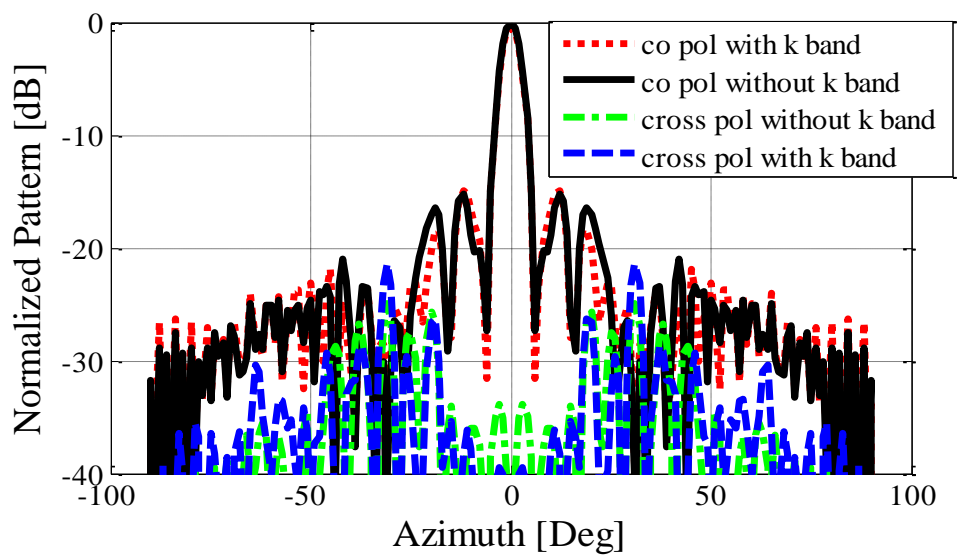

Fig. 18. Normalized pattern and cross polarization of $\mathrm{X}$ band array. 


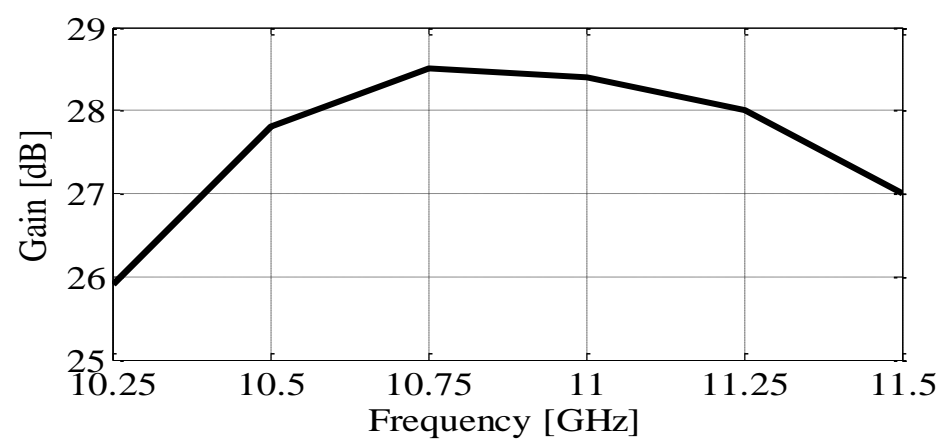

Fig.19. The simulated gain versus frequency.

The performance of our designed antenna is compared with previous dual band works in table 1 . Comparing pervious works with our proposed antenna, it is concluded this antenna has better efficiency in both bands. Also, this works has better bandwidth in comparison with [1]. So it is concluded the proposed antenna introduced in this communication has better efficiency and its $1 \mathrm{~dB}$ bandwidth is acceptable. Also due to symmetric shape of the unit cell, it has a very low cross polarization.

TABLE I. COMPARISON OF THIS WORK WITH PERVIOUS WORKS.

\begin{tabular}{cccccc}
\hline Reference & {$[2]$} & {$[9]$} & {$[1]$} & {$[6]$} & This Work \\
\hline Frequency (GHz) & 8.5 & 10 & 8.4 & 10.2 & 11 \\
& 18 & 13.58 & 32 & 22 & 21 \\
Efficiency & $40 \%$ & $51 \%$ & $52 \%$ (with Ka band) & $47 \%$ & $54 \%$ (with K band) \\
& $36 \%$ & $51.4 \%$ & $60 \%$ (without Ka & $25 \%$ & $60 \%$ (without K \\
& & & band) & $42 \%$ & band) \\
1-dB BW & $11 \%$ & $5.5 \%$ & $0.5 \%$ & $16 \%$ & $50 \%$ \\
$(\%)$ & $12 \%$ & $2.9 \%$ & $1.5 \%$ & $9.1 \%$ & $9 \%$ \\
SLL(dB) & $<-16$ & $<-22$ & $<-16$ & $<-15$ & $-15 \%$ \\
& $<-15$ & $<-20$ & $<-20$ & $<-20$ & -18 \\
Cross-Pol & No Data & -27 & -30 & -23 & -40 \\
$(\mathrm{~dB})$ & & -27 & -20 & -25 & -40 \\
\hline
\end{tabular}

\section{CONCLUSION}

A new analytical method to design FSS-backed RAs is suggested in this communication. With the use of this technique, a dual band antenna is designed and simulated. This suggested antenna operates at $\mathrm{X}$ and $\mathrm{K}$ band with $54 \%$ and $50 \%$ efficiency, respectively. Also $1 \mathrm{~dB}$ gain bandwidth of $\mathrm{X}$ band and $\mathrm{K}$ band are $9 \%$ and $10 \%$, respectively. Due to symmetric shape of the offered unit cell, the attained cross polarization is low (about $-40 \mathrm{~dB}$ ). The results are compared with previous works which prove good operation for designed antenna.

\section{REFERENCES}


[1] M. R. Chaharmir, J. Shaker, and H. Legay, "Dual-band Ka/X reflectarray with broadband loop elements," IET Microw. Antenna Propag.,vol. 4, 1ss. 2, pp. 225-231, 2010.

[2] Iman Derafshi, Nader Komjani, Ensieh Ghasemi-Mizuji and Mohammad Mohammadirad," Dual-band X/Ku Reflectarray Antenna Using a Novel FSS-Backed Unit-Cell with Quasi-Spiral Phase Delay Line" JMOE, Vol. 15, No. $3, \mathrm{pp} 225-236,2016$.

[3] C. Han, J. Huang, and K. Chang, "A high efficiency offset-fed X/Ka-dual-band reflectarray using thin membranes," IEEE Trans. Antenna Propag.,vol. 53, no. 9, pp. 2792-2798, Sep. 2005.

[4] M. R. Chaharmir, J. Shaker, N. Gagnon, and D. Lee, "Design of broad-band, single layer dual-band large reflectarray using multi open loop el-ements,'IEEE Trans. Antennas Propag.,vol.58, no. 9, pp. 2875-2883,Sep. 2010.

[5] I. Derafshi, N. Komjani and M. Mohammadirad, "A Single Layer Broadband Reflectarray Antenna by Using Quasispiral Phase Delay Line,” IEEE AWPL,vol. 14, pp. 84-87, 2014.

[6] R. Shamsaee Malfajani and Zahra Atlasbaf, "Design and Implementation of a Dual-Band Single Layer Reflectarray in $\mathrm{X}$ and K Bands IEEE Trans. Antenna Propag., VOL. 62, pp4425-4430, 2014.

[7] M. Rafaei-Booket, Z. Atlasbaf, and M. Shahabad, "Broadband Reflectarray Antenna on a Periodically Perforated Substrate" IEEE Trans. Antenna Propag., vol.64, pp 3711 - 3717, 2016.

[8] Rafael Florencio, José A. Encinar, Rafael R. Boix, Vicente Losada and Giovanni Toso, "Reflectarray Antennas for Dual Polarization and Broadband Telecom Satellite Applications", IEEE Trans. Antenna Propag., VOL. 63, NO. 4, pp $1234-1246,2015$

[9] Fei Xue, Hongjian Wang and Min Yi1, "Design of X/Ku Dual-Band Dual-Linear Polarization Reflectarray Using Double Parallel Dipole Elements” Progress In Electromagnetics Research C, Vol. 66, pp11-20, 2016.

[10] J. Huang and J. A. Encinar, Reflectarray Antennas. New York: IEEE Press, Wiley-Interscience, 2008.

[11] L. Li, Q. Yuan, K. Sawaya, T. Maruyama and T. Furuno, "Frequency Selective Reflectarray Using Crossed-Dipole Elements With Square Loops for Wireless Communication Applications" IEEE Trans. Antenna Propag., vol.59, pp 8999, 2011.

[12] Mahmoud Fallah, Alireza Ghayekhloo and Ali Abdolali," Design of Frequency Selective Band Stop Shield Using Analytical Method", Journal of Microwaves, Optoelectronics and Electromagnetic Applications, Vol. 14, No. 2,pp217228, December 2015

[13] C. R. Simovski, P. De Maagt, and I. V. Melchakova, "High-impedance surfaces having stable resonance with respect to polarization and incidence angle“,IEEE Trans. Antenna Propag., vol.53, pp 908-914, 2005.

[14] M. R. Chaharmir and J. Shaker, "Design of a Multi-Layer X/Ka-Band Frequency Selective Surface- Backed Reflectarray for Satellite Applications”, IEEE Trans. Antenna Propag., vol.63, pp 1255 - 1262, 2015. 